Summer 8-22-2019

\title{
Increasing Social Participation in Senior Center Through Program Development
}

\author{
Diana Dinh \\ University of St. Augustine for Health Sciences
}

DOI: https://doi.org/10.46409/sr.THDZ4487

Follow this and additional works at: https://soar.usa.edu/capstones

Part of the Occupational Therapy Commons

\section{Recommended Citation}

Dinh, D. (2019). Increasing Social Participation in Senior Center Through Program Development. [Doctoral project, University of St Augustine for Health Sciences]. SOAR @ USA: Student Capstone Projects Collection. https://doi.org/10.46409/sr.THDZ4487

This Capstone is brought to you for free and open access by the Student Research at SOAR @ USA. It has been accepted for inclusion in Student Capstone Projects by an authorized administrator of SOAR @ USA. For more information, please contact soar@usa.edu, erobinson@usa.edu. 


\section{INCREASING SOCIAL PARTICIPATION IN SENIOR CENTER THROUGH PROGRAM DEVELOPMENT}

by

Diana Dinh

A Capstone Project Proposal Presented in Partial Fulfillment of the Requirements for the Degree of DOCTOR OF OCCUPATIONAL THERAPY

University of St. Augustine for Health Sciences

August, 2019 
INCREASING SOCIAL PARTICIPATION IN SENIOR CENTER THROUGH PROGRAM DEVELOPMENT

by

Diana Dinh

has been approved

August, 2019

APPROVED:

Erin Schwier, EdD, OTR/L, Program Director

Susan MacDermott, OTD, OTR/L, Doctoral Coordinator

ACCEPTED AND SIGNED:

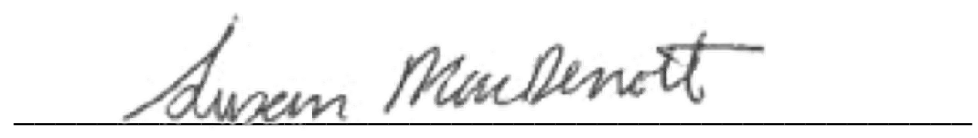

Susan MacDermott, OTD, OTR/L, Doctoral Coordinator

eschwier@usa.edu Digitally signed by eschwier@usa.edu

Date: 2019.08.21 11:21:17 -07'00

Erin Schwier, EdD, OTR/L, Program Director 


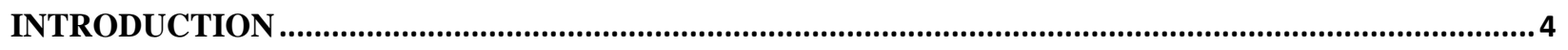

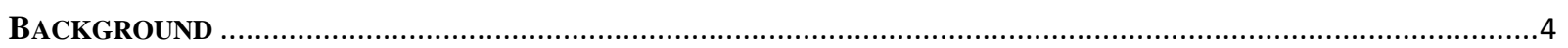

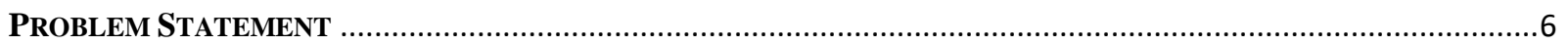

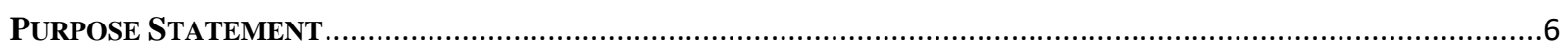

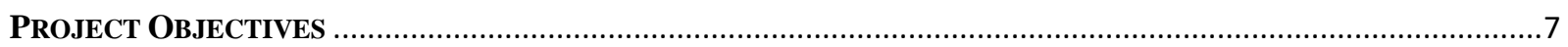

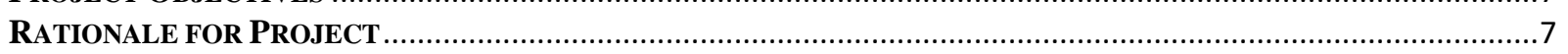

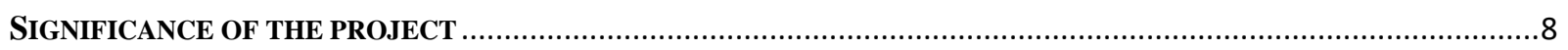

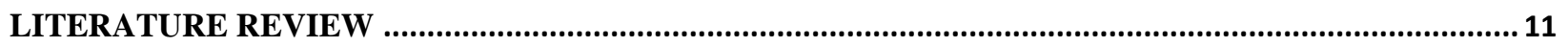

INTRODUCTION

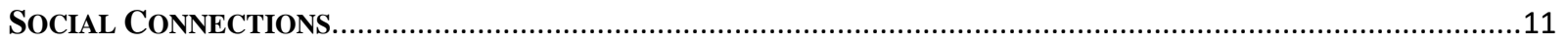

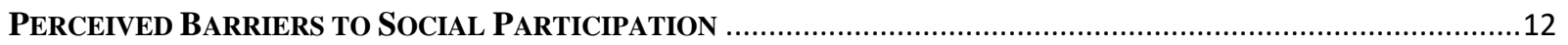

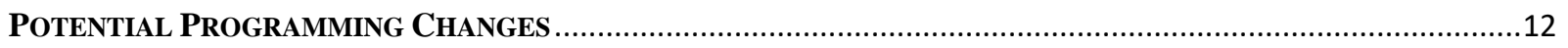

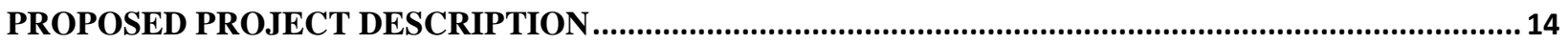

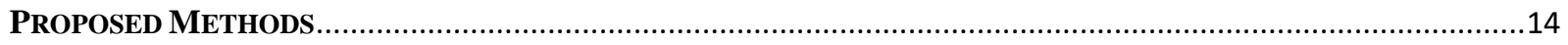

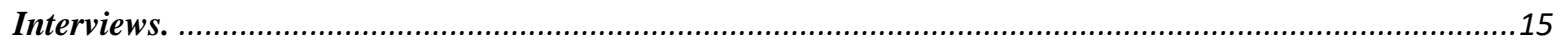

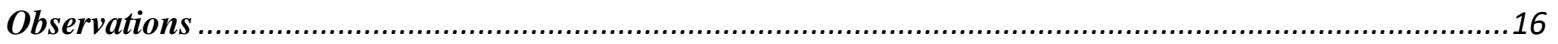

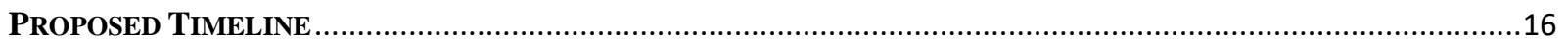

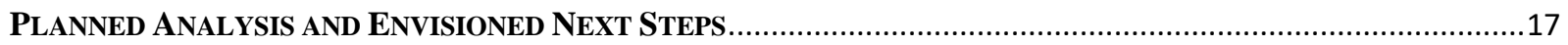

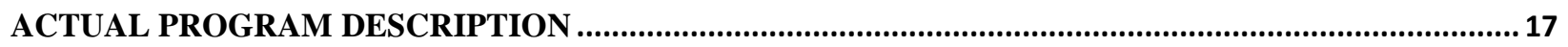

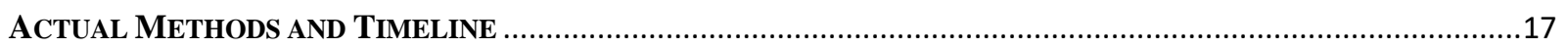

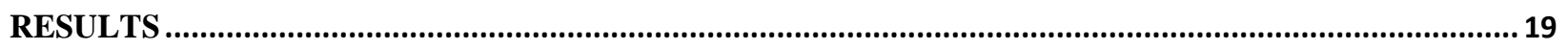

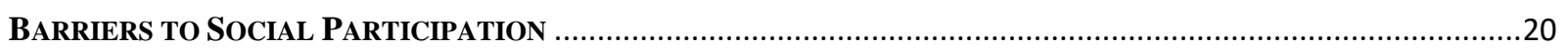

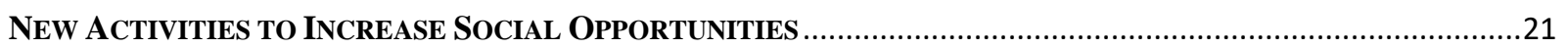

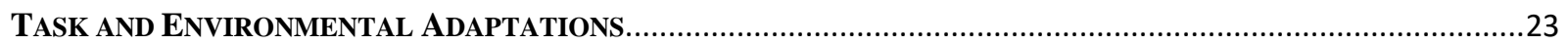

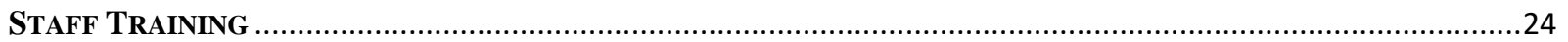

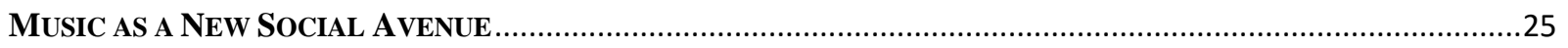

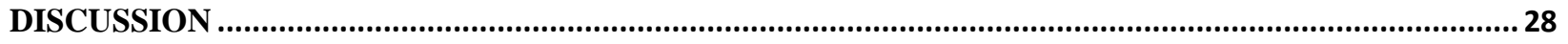

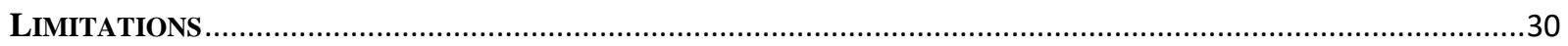

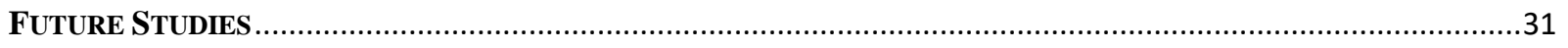

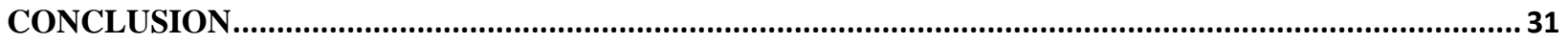

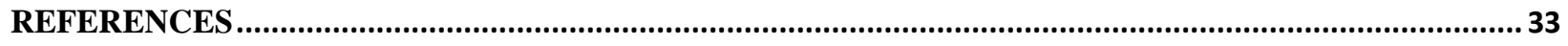

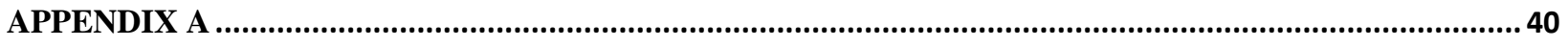

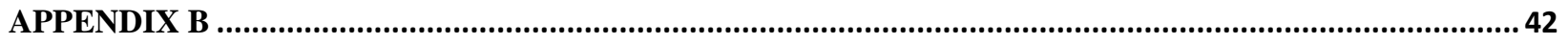

APPENDIX C

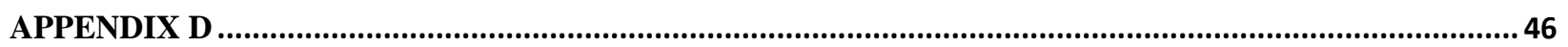

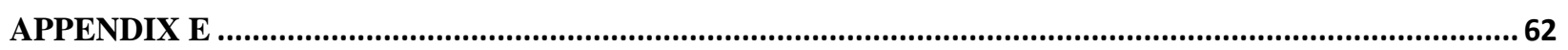

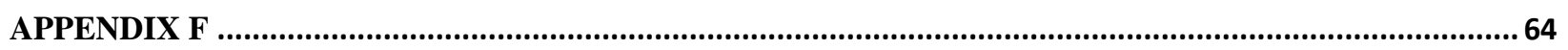

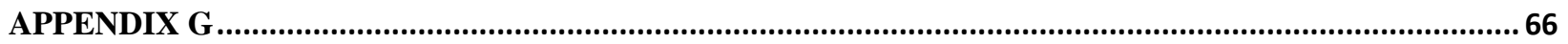




\section{Introduction}

\section{Background}

Within 30 years, the population of older adults residing in the United States is expected to reach nearly 84 million (Smallfield \& Molitor, 2018). This significant rise highlights the importance of facilitating healthy and successful aging among older adults. Healthy aging, for the purposes of this project, will refer to the continued engagement in occupations. Occupation is defined as the daily life activities that people engage in, which have purpose and utility, and provides individuals to live meaningful and productive lives (Smallfield \& Molitor, 2018).

A critical aspect of healthy aging is to remain socially active within the community. According to activity theory, as described by Robert Havighurst, older persons who remain socially active can better adjust to the aging process because they engage in social roles that are essential for the maintenance of positive self-image, which in turn is associated with high life satisfaction (Jefferson, 1999). Activity theory emphasizes the importance of continuing activities that are lost through retirement, or at least replacing it with other meaningful activities. Actively engaging in social activities with others can enhance self-determination by promoting independence, creating social networks, and fostering continuity (Dattilo et al., 2015).

Over the last decade, senior centers have increased in numbers to help facilitate healthy aging among community-dwelling older adults (Hurley et al., 2014). These centers are community focal points for aging which provide seniors with opportunities to socialize, participate in recreational activities, and health and support services. They can also offer a range of educational opportunities that promote learning, creativity, and skills development, and are ideal venues for health promotion interventions. According to Dattilo et al. (2015), one of the 
most prominent reasons why seniors attend senior centers was the opportunity for social interactions because it provided connectedness. Although the types of available recreation activities were important, seniors were more interested with whom they did the activities with (Dattilo et al., 2015).

There is increasing evidence of the role of occupational therapists in facilitating healthy aging in community-dwelling older adults (Papageorgiou, 2016). However, there is lack of evidence that identifies the unique contribution of occupational therapy in promoting social participation among older adults in senior centers. Occupational therapists use occupational engagement to empower individuals and populations to achieve their health, wellbeing and participation (AOTA, 2014). Their programs and interventions for older adults largely focus on the maintenance or facilitation of social participation, functional independence, and quality of life (Papageorgious, 2016). This project will focus on the aspect of social participation. Social participation is defined as social interdependence, via involvement in occupations that facilitate social situations with others, such as the community, family, peers, and friends (AOTA, 2014). An absence of social participation may hinder healthy aging and lead to social isolation. Older adults are at greater risk of social isolation because they are more likely to live alone, lose a significant other, have a chronic illness, and experience transportation or mobility difficulties (Smallfield \& Molitor, 2018). Due to these factors, older adults have an increased risk of developing other health issues, such as stress and depression, which can influence physical, emotional, and psychological health. Therefore, addressing social isolation among older adults is an important community and public health concern. Health professionals, such as occupational therapists, have the ability to contribute to the prevention of social isolation among older adults by promoting social participation. 


\section{Problem Statement}

As more people are living longer, there is an increased need to provide care to promote healthy aging. Senior centers are increasingly important in helping older adults maintain their general health, wellbeing, and independence (Hurley et al., 2014). There are increasing evidence that senior centers provide physical and social benefits for community dwelling older adults, but these studies had little focus on social programming and its potential for improvements. A study by Hurley et al. (2014) showed that changes to a center's organizational structure, physical environment and work practices may increase opportunities for activity involvement. However, this study focused more on increasing physical participation than social participation. A richer understanding of the current experiences in senior centers in the context of social participation is needed. This capstone will contribute to this gap by assessing what changes in social programming are appropriate to enhance social participation in senior centers.

\section{Purpose Statement}

The purpose of this proposal is to promote social participation among communitydwelling older adults by evaluating the need for adapting or enhancing current social programming in order to provide more opportunities for engagement. The range of programs and activities available to participants at senior centers are extensive. This project will assess what changes are needed and, as appropriate, propose changes to create a more socially active and purposeful environment. Program recommendations may include strategies to enhance social engagement such as involving seniors in all aspects of planning events and through enhanced opportunities for social engagement, such as through technology or with intergenerational programs. 


\section{Project Objectives}

The objectives of this project are to (1) Familiarize with the culture of the senior center, (2) Assess current programming strengths and limitations through observation and staff and participant interviews, (3) Propose and introduce programming recommendations to increase social opportunities, and (4) Identify potential changes in participant satisfaction through interviews with staff and participants. Potential recommendations may include changes in the organization, environment, staff training, staff-member interaction, or introducing new social opportunities.

\section{Rationale for Project}

Project coordinators at San Marcos Senior Activity Center have expressed the need to enhance social interactions among their attendees. They have existing programs and activities that offer social benefits, however, their programs may benefit from an occupational therapy perspective. Occupational therapists can evaluate members' needs and interests and enhance existing programs to increase social engagement. Occupational therapy may also serve as consultants to the senior center and make modification suggestions to enhance member participation (AOTA, 2016).

The Person-Environment-Occupation (PEO) Model is an occupational therapy model that helps identify the interaction between the person, the environment, and the occupation (Schell, Gilen \& Scaffa, 2014). This model will be used to study social participation because it takes into consideration the effects of the environment and activity on the person. The PEO model provides a theoretical framework that can be viewed as an assessment tool to analyze areas that may affect social participation, or as an intervention tool to improve social participation by changing one of the three domains (Fox et al., 2017). In this project, the 'person' will refer to 
older adults who are currently attending the San Marcos Senior Activity Center. In order to understand how center attendees engage in social activities, it is essential to know their personality, level of physical and cognitive health, spirituality, and social interests and needs. The environment of the senior center is also important to note because it determines the level of social participation that occurs. The culture, social supports, and access to the center are examples of possible features of the environment that will be observed. The 'occupation' will focus on social participation at the center and how it is affected by a person's factors.

\section{Significance of the project}

The role of occupational therapy in the community is expected to rise to meet the growing number of older adults in a fast-changing health care environment (Smallfield \& Molitor, 2018). It is important to prepare future occupational therapy practitioners to meet the needs of seniors living in the community, including social participation. Social isolation among older adults may be due to lack of social opportunities, knowledge in activities, or interest, thus it is important to address these challenges and provide solutions (Fox et al., 2017). A limited amount of research has been conducted on social participation at senior centers in the last decade. This project will focus on determining the characteristics of current center programming and the extent of social participation among the elderly population. It will explore what kinds of programs and resources are most appropriate in providing the social needs of an increasingly diverse older population. The findings of this project may be used to inform future occupational therapy practice on what types of changes are needed to enhance social participation among older adults who attend senior centers. 


\section{Assumptions, Limitations, and Delimitations}

Some assumptions were made for this project. It is assumed that the current programs at the senior center need improvements. Although this may not be true, a study by Hurley et al. (2014) showed that changes in the organization and environment in senior centers can increase the physical and social experiences of its attendees. For instance, senior center staff wants what is best for their attendees and often do things for them that they could do for themselves (Hurley et al., 2014). By re-training staff to encourage more independence among their attendees, attendees came to appreciate their own capabilities and thereby had more opportunities to engage in activities with others. Therefore, this study will identify any programming challenges and provide recommendations for improvements to enhance social participation. There is also an assumption that older adults are in need of an intervention for social participation. It is possible that these participants may already have a wholesome social life and do not need assistance. Although this may be true for some older persons, it was found that about 35\% of U.S. adults over age 45 are lonely (Smallfield \& Molitor, 2018). Senior centers can serve as an important source of social support for the elderly by providing opportunities for the maintenance of social networks (Dattilo et al., 2015). An example of this can be seen by a quote by a senior center participant: "Before I came here, I was all by myself...now I have all kinds of friends now" (Dattillo et al., 2015, p. 381).

There are some limitations that may occur in this project that need to be considered. First, social participation may be affected by the time frame of this project. The project is projected to occur from May to June. Since it overlaps with summer time, it is possible that attendees may have other obligations, such as going on vacations, and would not attend consistently. Also, the availability of certain programs will vary depending on the time of year, which may change the 
types of social opportunities offered. Second, transportation to the senior center may also affect senior center attendance and participation. For instance, current attendees may stop attending the center due to lack of transportation. Third, there may be age-related health conditions that may limit participant's social participation, such as physical, mental, or cognitive diseases. Fourth, the cost of developing new activities may be expensive, which may affect the variability in activities offered at the center. Lastly, the purposive sampling procedure decreases the generalizability of findings. Since this project will only be done at one site, the findings of this project should be treated with caution because the changes in programming may not be replicated in other care facilities due to organization and demographic differences.

At the request of the center for a partnership as willing participants, this project will be carried out at the San Marcos Senior Activity Center. It will focus solely on the San Marcos culture, demographic, and social programming. This study will also confine itself to staff and user interviews and observations. Interviews are far more personal than questionnaires and will help us better understand opinions, behavior, and experiences. Activities have been preselected as possible avenues to promote social participation, such as technology and intergenerational programs. There is an abundance of evidence that showed the association between these two avenues to increased social participation among older adults. There is strong evidence that incorporating technology use, such as the Internet, in everyday life can promote a sense of empowerment (Ekel et al., 2017) and increase social connections among older adults (Nyman \& Isaksson, 2015). Many older adults have expressed interest in learning how to use technology, but reported several drawbacks, such as lack of confidence and knowledge. This project will address these barriers and provide technology education to those who may need them. For this project, technology will refer to learning how to take pictures and sharing them online in a 
community blog. Intergenerational programs are also known to increase social participation among older adults. In Morita and Kobayashi's study from 2013, it was seen that older adults enjoyed their interactions with preschool children because it gave them the opportunity to nurture and mentor children, which translated to greater sense of self-worth. Intergenerational programs in this project will refer to older adults engaging in social activities with younger children, to share their skills, knowledge, or experiences. These activities may include gardening, arts and crafts, reading, and music.

\section{Literature Review}

\section{Introduction}

Senior centers are ideal locations to deliver health promotion programs to the growing population of older Americans. The purpose of this literature review is to explore the role of senior centers in facilitating social participation as seen in research. It will review evidence that shows the social support senior centers provide to their attendees, and examine perceived barriers to social engagement. Future program development recommendations will also be provided, as suggested from the literature.

\section{Social Connections}

The theme of social connection at the senior center was present across multiple studies. Dattilo et al. (2015) found that older adults attended centers for three reasons: to learn about new activities and places, to engage in recreational activities, and for the opportunity to make social interactions. Attendees frequently identified that senior centers provided them a sense of relatedness and connectedness, due to having similar recreational interests and allowed for new friendships. A woman said, "When you live by yourself, this is your extended family... they're just like family to me, you know" (Dattilo et al., 2015, p. 382). Such comments illustrate the 
social support senior centers may provide for older adults. This finding is consistent with research by Fox et al. (2017), which found that senior centers were a community place that provided context to develop valuable friendships that extended beyond the center. A similar study by Lorek et al. (2017) found that leisure engagement in senior center programs provided a natural way for older adults to socialize.

\section{Perceived Barriers to Social Participation}

To date, there is not much evidence about the specific barriers of social engagement in senior centers. However, there are studies that can provide insight into reasons why older adults may not participate in organized and social activities. Fox et al. (2017) found that lack of activity engagement was due to older adult's perception of not having enough opportunities and because they had no one to participate with. Although facilities may offer a variety of activities, older adults were either uninformed or unable to recognize these opportunities, thus affecting their engagement. This is supported by another study by Buffet et al. (2013) that found that older adults who were informed or directly asked to participate in activities were more likely to engage in social and voluntary activities. Also, the perception of not having anyone to do activities with suggested that although older adults may know the people in their facility, they may not feel comfortable with them as activity companions or friends (Fox et al., 2017). These findings call for interventions that may help older adults experience increased social engagement.

\section{Potential Programming Changes}

The challenge is thus to find ways for individuals to increase their social participation. A study by Vivoda \& McGuire (2017) found that older adults who invited friends to attend programs with, were more engaged in social activities at the center on average than those who did not. This finding highlights the potential importance of having a support or "buddy system" 
in order to increase social engagement among their attendees. Other studies also showed that changes in the culture, structure or environment of a senior center may improve social interactions. Santo (2009) found that the type of environment that activities were offered in can impact social behaviors or withdrawal. This review argued that a beneficial environment for senior centers should be ones that facilitate active learning, such as those that include multiple avenues for attendees to socialize, showcase their products, and share their knowledge (Santo 2009). A similar study by Hurley et al. (2009) also showed that changes in the organizational structure of a day center, such as re-training staff members, could promote engagement among their attendees. Although this study focused on enhancing physical engagement, it also saw improvements in social opportunities for user engagement. Changes in program content should also be considered. Findings from Fox et al. (2017) challenges the idea that offering programs or activities at a senior center may not be sufficient on its own. Instead, it argues that future intervention development should also include the process of helping older adults identify their options. This is supported by Lorek et al. (2017), in which attendees reported interest in making more decisions about their social engagement opportunities, such as working with the program coordinators to create new volunteer programming or finding various ways to become more engaged with their communities.

Although there is research that has studied the benefits of senior centers among older adults, the evidence on specific programs or interventions on social participation offered through senior centers are limited. There is a need to evaluate specific programs and how it can impact the social lives of older adults. Therefore, this capstone project will aim to evaluate current programs at the San Marcos Senior Activity Center and provide insight into what changes may be needed to increase social participation among their older adult attendees. 


\section{Proposed Project Description}

\section{Proposed Methods}

Qualitative methods using an ethnographic approach will be used in this project to understand the satisfaction and participation in social occupations of older adults at the San Marcos Senior Activity Center. An advantage of using a qualitative design is that those methods seek to describe how individuals perceive their own experiences within a specific social context (Portney \& Watkins, 2015). Particularly, this project will focus on the perception of social participation among senior center attendees and how it may change through program development. It will explore the nature of people's relations with themselves, others, and their surroundings (Portney \& Watkins, 2015).

A convenience sample design will be used for recruitment because participants will be chosen on the basis of availability. The target population will be older adults who are currently attending the San Marcos Senior Activity Center in San Diego, California. Participants will be recruited with the assistance of senior center directors and program coordinators using the criteria of older adults who regularly attend and use this senior center for at least twice a week (Lorek, 2017). Instead of randomly bringing in new people to the center, current senior center attendees will be encouraged to use their social relationships within the center to recruit other attendees. Program coordinators will first introduce senior center staff and attendees about the project one month prior to the project to prepare them. On the first day of the project, the student will introduce the goals of the project to their staff and attendees and discuss about any potential questions or concerns they may have. Participants will then be verbally invited to participate in the project. Recruitment will rely on the snowball effect, as it is less disruptive to the center and its attendees (Creswell, 2014). This type of method is chosen because it studies personal 
networks and social relationships (Portney \& Watkins, 2015). There is no limit to the sample size, however we hope to have at least 25 participants.

Data collection will be accomplished through semi-structured interviews and observations. Interviews can provide crucial information about individual experiences and how they behave and act within their context (Creswell, 2014). Interviews are useful in obtaining detailed information about personal feelings, perceptions and opinions of their experiences at the center. This is especially important for this project, as social participation is dependent on attendees' interests and motivation. Observations will also be used to observe behavior as it provides insights about how attendees engage in social activities, as well as how current programs are designed and implemented. It also provides a chance to learn behaviors and beliefs that people may be unwilling to discuss in an interview (Creswell, 2014).

Interviews. Prior to any interviews, staff and attendees will be asked to verbally consent to having their interview be recorded on tape (See Appendix A). Participants will be interviewed two times throughout the project. The first group interview will occur at the beginning of the project, after rapport is built between the student and senior center staff and attendees. Individual interviews will also be offered if staff and attendees are comfortable with one on one interaction. A second group interview will follow at the end of the project to compare if attendees' social experiences differed in any way. Interviews will be conducted in groups during lunch time, as this adds valuable insight into the group dynamics of the center. According to the coordinators of the senior center, having group interviews during lunch time is the best time for interviewing, as this time is embedded in their normal routine and would be less disruptive. The semi-structured interviews will provide information to several key questions, as well as allows participants to deviate and respond in more detail (Gill et al., 2008). Questions will be adapted from two 
previous studies in order to generate similar responses (Novek et al., 2013; Hurley et al., 2014). It will include questions about their pre and post experiences, such as any barriers they have faced, and about their experiences with the changes. (See Appendix B).

Observations. Participant observation technique will be used to understand the culture and social behavior of staff and attendees at the senior center (Portney \& Watkins, 2015). The student will participate in the same activities as attendees to have the same experiences, which will provide important insights into behaviors or situations (Creswell, 2014). Observations will be gathered using field notes, and will include key areas taken from existing tools, such as the Facility Tool and Program Evaluation tool, to assess how well the senior center is doing in terms of facilitating social integration (Novek et al., 2013). (See Appendix C). Observations will include social behavior, such as staff-user and user-user interaction, as well as descriptions of how programs are delivered and its impact on user's social engagement in activities.

\section{Proposed Timeline}

The duration of the project is expected to range from 12-16 weeks. In order to familiarize with the culture of the San Marcos Senior Activity Center, the student will be volunteering in activities for the first three weeks of the project. During this time, the student will observe how members engage in activities, the sociocultural influences on social participation, as well as the design and structure of current programs. Once rapport is built with staff and attendees, group or individual interviews will be conducted during lunch time. This is anticipated to occur around the fourth week of the project. Group interviews will be conducted with each table, ranging from about 5-8 attendees. Interviews are estimated to last about 30-60 minutes each group. Due to time constraints, interviews will be conducted in a series of days or up to a week, as it is not possible to interview every group in one lunch day. The second month will be the program 
development phase, where the student will collaborate with staff and attendees in identifying and proposing program changes to enhance social participation. During this month, some of these recommendations will be implemented, such as adapting or enhancing certain programs. The third month of the project will focus on observing for any changes in social engagement and interactions between staff and attendees. Interviews will be conducted again to identify any changes in satisfaction with social participation at the center. For instance, comparing key words or phrases during interviews, such as "better," "same," "no difference." If it appears that there are no big changes in social participation, recommendations for future program revisions will be provided. Near the end of the project, senior center attendees will be encouraged to share pictures or showcase their projects with their friends and family.

\section{Planned Analysis and Envisioned Next Steps}

All audiotapes and fieldnotes will be collected by the student. Qualitative data from interviews and observations will be analyzed using open coding. Audiotapes and field notes will be transcribed and typed into a Microsoft Word document and used as data. Key words and phrases from the transcripts will be organized into common categories and hand coded for themes. Once themes are created and interpreted, findings will be disseminated via poster presentation at University of St. Augustine for Health Sciences in San Marcos, California. Findings will also be presented to the San Marcos Senior Activity Center staff.

\section{Actual Program Description}

\section{Actual Methods and Timeline}

The duration of the project was 13 weeks. The first two weeks of the project was focused on familiarizing with the culture of the senior center. This time included participating in classes and programs and observing the dynamic between the activity leaders and seniors. Ideally, it was 
expected that fieldnotes would be taken during classes, but in actuality, activity leaders preferred the student to participate directly with the class, instead of observing in the back and writing notes. Therefore, field notes were written after classes ended. The observation guideline was also updated to address factors that were not initially considered, such as the design of the class from beginning to end.

Staff, seniors, and long-term volunteers were interviewed for this project. Volunteers were also interviewed because they showed good understanding of how the senior center functioned and had good relationships with the seniors. Formal interviews were expected to start on the second or third week of the project. However, many participants at the center were more open to sharing than expected, and informal interviews actually began during the first week. Informal interviews consisted of casual conversation and did not use all of the interview questions. Their responses were not recorded, but key words were written in a notebook, then their responses were asked about in more detail during the formal interviews the following week. Interviews did not only take place in the cafeteria room, as planned, but was also conducted in the hallways and classes of the center. This was because not all regular attendees who attended classes attended the nutrition program, also known as lunch. Formal interviews lasted an average of 5-10 minutes, depending on seniors' availability and talkative nature. Initially, interviews were expected to span within a week. However, there were some seniors who were more reserved than others and needed multiple, shorter interviews, thus pushing the interview timeline back. Also, it was not realistic to have interviewed all regular attendees within a week, since many seniors were not available for interviewing due to having other commitments, such as work, volunteer, family, or doctor appointments. Additionally, there were many seniors who constantly shared their opinions, thus it made more sense to interview seniors on a continuous 
basis, rather than the original one week as planned. This change was beneficial to this project, as this flexibility provided seniors time to think and make suggestions at their convenience.

Initially, a second interview was planned to occur at the end of the project to compare if attendees' social experiences differed in any way after recommendations were made. However, due to the short duration of the project, it was too soon to see any big changes, thus no post interviews were conducted. However, potential post interview questions will be provided in Appendix B for future references.

Data collection was discontinued after about two months since there was a repetition in responses and observation. Data from the field notes and audiotapes were transcribed onto a Microsoft Word document and coded into major themes and categories.

\section{Results}

There was a total of 30 participants, with 22 seniors and 8 staff including volunteers, that were interviewed for this project, and ten classes that were observed. Although there was a good ratio of male and female seniors at the senior center, the majority of participants that took part in classes were female. Popular activities among male participants included playing pool, playing the ukulele, water aerobics, and fitness classes, whereas female participants enjoyed fitness and dancing classes, bingo, and mixed media classes, such as painting. The age range at the senior center was roughly between 65-103 years old, therefore there was a variety of roles and engagement patterns that was observed among senior attendees. The younger older adults were participating in more leisure classes than the older seniors, whereas the older seniors held more volunteer roles at the senior center such as maintaining the library, signing attendees in for the lunch program, and preparing lunch. 
Although there was a total of six questions asked, most seniors only answered about four, due to confusion on some of the wording and because of a language barrier. Therefore, questions were changed for each interviewee to encourage responses. Through observation and interview responses, five major themes were found: there were multiple barriers to social participation at the center, a need to design more activities to increase social opportunities, a need for task and environmental adaptations, a need for staff-training, and music as a potential medium to increase social engagement (See Table 1).

Table 1. Overview of Major Themes

\begin{tabular}{|l|l|}
\hline \multicolumn{1}{|c|}{ Themes } & \multicolumn{1}{c|}{ Examples: } \\
\hline Barriers to Social Participation & - Scheduling Conflicts \\
& - Limited selection of activities after lunch \\
& - Transportation \\
& - Lack of awareness of available options \\
& - Age and health-related issues \\
& - Activity costs \\
\hline Need for New Social Activities & Such as more: \\
& - Outdoor activities \\
& - Lunch activities \\
& - Opportunities to evaluate program content \\
\hline Need for Task and Environmental & - Provide adapted equipment \\
Adaptations & - Environmental modifications (lighting, table \\
& positioning, protective flooring) \\
& - More visual aids \\
\hline Need for Staff-Training & - On how to adapt tasks to promote participation \\
& - On how different impairments can impact physical \\
& and social participation \\
\hline Music as a Social Avenue & - Seniors were more sociable when music was \\
& involved \\
\hline
\end{tabular}

Barriers to Social Participation. Interview responses indicate six main limiting factors to senior's social engagement, in order from most to least commonly stated: scheduling conflicts, lack of available classes of interest, transportation, lack of awareness of available opportunities, health-related issues, and high activity costs. However, only a few of these concerns were 
actually observed, such as scheduling conflicts, limited classes offered after lunch, transportation, and age and health-related issues. Some seniors were not able to participate in certain classes because it overlapped with another class or because they were busy with other obligations, such as work, family, or volunteer work. Transportation was another common barrier that was observed. Seniors who used the lunch shuttle program did not have the opportunity to participate in after lunch activities or classes due to inflexible pick-up schedules. Since the lunch shuttle program was offered through the school district, pick-up schedules were set and could not be changed. Although these seniors were made aware of other transportation options, most seniors expressed disinterest and accepted their current situation. Another barrier was the limited selection of classes offered after lunch. Although there were classes offered, the number of participants were lower than those in the morning. One of the seniors mentioned that they usually leave after lunch because there was "not a good selection of classes after lunch as the ones [provided] in the mornings." Common health-related barriers that were mentioned in interviews and were seen to impact occupational performance include pain and joint stiffness due to osteoarthritis or rheumatoid arthritis, hand tremors due to Parkinson's, memory loss due to mild Dementia, residual effects of a stroke, and age-related symptoms, such as visual impairments, hearing loss, and loss of balance. Although the senior center used a variety of marketing strategies to announce upcoming events or services, such as through public announcements during lunch, flyers, and their newsletter, many seniors were still unaware of available opportunities. This suggests that staff may need to find a different strategy to assist seniors in exploring their options, such as designing an activity exploration program.

New Activities to Increase Social Opportunities. The interview responses showed that seniors were mostly content with their experiences at the senior center. When asked about their 
reasons for attending the senior center, they said that it provided them with opportunities to socialize with friends and to stay busy with recreational activities. One of the seniors said that the senior center was "a good place to meet people and do activities together," while another senior similarly mentioned that the center helped her "made new friends that liked to do what [she] do[es]." Although most seniors were content with current social programming, there were some seniors who expressed concerns and asked for more social opportunities. For instance, a senior complained that there was a lack of lunch activities, stating "We just sit and wait [for our lunch]. There's nothing to do." Another senior also mentioned that he does not participate in any activities at the center because there was a lack in variety of activities of interest, stating "Maybe more activities. There's bingo, but I don't like to play bingo. There's art, but I don't paint." These statements suggest the need for staff to collaborate with seniors in designing new, meaningful activities at the center.

Interview responses reveal that seniors at this center are interested in having more outdoor activities. Several studies have shown that outdoor activities can help older adults maintain their social well-being. For instance, an outdoor mindful walking program was linked to improved mental health, as well as increased participation in community life and social events (Eronen et al., 2014; Yang \& Conroy, 2019). The time spent in nature also improved physical well-being, mood, mental acuity, and quality of life in older adults (Eigenschenk et al., 2019). Therefore, senior centers should consider offering a variety of outdoor activities to meet this need.

Another potential activity that the center should consider is to have their seniors collaborate with staff in program content development at the center. It was observed that seniors did not play a role in deciding what types of classes or social event the center had. There was a 
suggestion box available in the hallway for any comments that seniors may have, but this was not commonly used. Having seniors be more proactive in choosing the types of activities or classes they are interested in may influence higher participation and increase more social opportunities.

Task and Environmental Adaptations. From observations, the majority of the older adults at this senior center did not require a lot of assistance in participating in classes and activities. For seniors who did need assistance due to either health or age-related symptoms, staff did a respectable job in providing accommodations, such as slowing down the pace of an activity, repeating directions, and providing different grading options during fitness classes. The physical environment at the senior center was well designed, as there was decent lighting and contrast in the hallways and classrooms for good visibility, adequate spacing between tables for safe functional mobility and participation, and secure upper-body supports such as handrails or grab bars in the hallways and restrooms for fall prevention.

To enhance occupational performance and promote social inclusion, additional adaptations and environmental modifications were recommended to staff. For instance, it was suggested for older adults who participated in painting classes that a maulstick or adapted version of this simple tool be provided to them, in order to help stabilize tremoring hands. Class leaders were also recommended to provide a variety of visual aids, such as handouts and large posters, for multi-step activities to aid seniors in following directions. It was also suggested to increase lighting in the library room, to provide better visibility, as well as repositioning the table to prevent glares during puzzle activities. Protective flooring, such as rubber mats, was also recommended for the outdoor fitness zone, as the concrete floor was not safe for seniors to 
exercise on. See Appendix D for additional examples of potential accommodations and adaptations given to staff.

Staff Training. Staff training was another theme that was commonly brought up during interviews with staff and seniors. Staff members indicated interest in learning how to address seniors with cognitive impairments. Many mentioned that they have met many seniors with dementia, but were not trained in how to handle difficult situations and on how to provide an environment that fosters participation. Some seniors also indicated the need for staff and volunteers to be trained in assisting visually impaired seniors with their occupations, with statements like: “Train volunteers to help. She can't see and needs help eating” and "There needs to be someone at lunch to help her. We can't help her all the time."

Observations showed that staff and volunteers should also be trained on grading tasks for seniors to create more opportunities for their involvement at the center. There were simple tasks that seniors could have played a larger role in, but instead was solely done by staff members for safety reasons, such as decorating the bulletin board and common areas. It was expressed by staff members that they were unsure of what their seniors could handle and believed that there were too many liabilities involved. Staff was then educated on different strategies to grade down tasks to promote safe participation for their older population. For instance, using tape instead of push pins, wrapping cloth around handles to reduce stress on joints, and to keeping decorations at a safe height to minimize fall risk. After these suggestions were applied, many seniors expressed gratitude for allowing them to be a part of the decorating committee and the opportunity to share their creative skills. This positive reaction supports the claim that senior centers should design interactions to do with seniors, and not just for them (Lawler, 2011). 
Music as a New Social Avenue. Initially, it was expected that technology would be a popular social avenue at the senior center. However, there was not a lot of interest in learning how to use their phones or the computer. Instead, music was found to be more attractive with this older population at the center. During lunch time, seniors were either seen sitting quietly among themselves or socializing with only people at their tables. However, during music socials or when there were live performances, these same seniors were seen dancing and socializing with other seniors from other tables. This positive reaction to music was a large development in the project because it showed that music was an avenue that could bring seniors together and influence social engagement at the senior center. With this new discovery, seniors were asked to collaborate together with the student to customize an ongoing playlist of their favorite songs to be played during meal time. During this group activity, seniors were encouraged to share their reasons for choosing that song and how music has impacted their life. By getting to know each other's interests and stories, seniors were able to create deeper ties to each other and their community.

Key results from observations and interviews were verbally presented to the head staff. A list of potential changes that seniors and staff have mentioned were provided during this meeting (See Table 2). According to the organization's policy, big social events and lunch activities usually requires about three months to prepare and plan for, therefore only simple recommendations were actually implemented during this project. These recommendations included having more volunteer or staff members walk around the senior center to initiate conversations with reserved seniors who needed encouragement to socialize, inviting seniors to participate in telling jokes during lunch time, adding more visual aids to accommodate seniors with memory loss (See Appendix E), providing seniors with more opportunities and roles at the 
center, and collaborating with seniors to create a music playlist based on their musical preferences to enhance their social experience. Other social programming recommendations, such as potential lunch activities and social events, were also created and sent to the head staff via email for initial approval (See Appendix F). These activities were created upon seniors' and staff input and are supported from past studies. For instance, the "Hobby Fair" event was created to encourage discovery and participation in new leisure activities. Past studies suggest that although older persons are less likely to start new activities, it is imperative that they remain aware of different recreations, as too much stability can lead to boredom, lack of motivation, and eventually depression (Leitner \& Leitner, 2012). Thus, creating a social event that promotes the exploration of new activities would be beneficial at the center. A binder filled with key findings from this project, including a final draft of lunch activities, will be presented to the senior center staff, prior to disseminating a poster presentation at University of St. Augustine for Health Sciences in San Marcos, California.

Table 2. Potential Changes

\begin{tabular}{|l|l|}
\hline \multicolumn{1}{|c|}{ Potential Changes } & \multicolumn{1}{|c|}{ Interview Responses } \\
\hline More outdoor activities & - "A walking program would be nice." \\
- "It's nice outside. It would be nice to do \\
something outside." \\
- "What about a fitness class outside. I don't' \\
know how to use those machines." \\
- "It's beautiful out there. We can do \\
something with nature." \\
- "Something different, like walking outside \\
or something." \\
- "Other centers have a walking class. They \\
don't have that here." \\
- "Maybe Tai Chi at the park." \\
- "A picnic outside would be nice, but I don't \\
think they would do it." \\
- "This was fun. We should have more \\
[outdoor] activities like this."
\end{tabular}




\begin{tabular}{|c|c|}
\hline More selection of activities & $\begin{array}{l}\text { - "I think we should have more jokes. } \\
\text { Laughing is a very powerful tool for seniors." } \\
\text { - "We just sit and wait. There's nothing to } \\
\text { do." } \\
\text { - "There should be more activities after } \\
\text { lunch." } \\
\text { - "Maybe more activities. There's bingo, but I } \\
\text { don't like to play bingo. There's art, but I } \\
\text { don't paint." } \\
\text { - "It's fine right now, but it would be nice to } \\
\text { have something to do during lunch." } \\
\text { - "I want to show my paintings." } \\
\text { - "We just watch tv or read. That's it." } \\
\text { - "I can help decorate. I love decorating...just } \\
\text { let me know beforehand." } \\
\text { - "I signed up to volunteer, but haven't heard } \\
\text { back." } \\
\text { - "We need more activities to increase } \\
\text { interaction." } \\
\text { - "Bring the Wii back." } \\
\text { - "I can help decorate for events. I love } \\
\text { decorating." } \\
\text { - "We should bring back the animal program. } \\
\text { A lot of people have asked about that. It was } \\
\text { such a fun program." } \\
\text { - "Something with our pets. I could bring my } \\
\text { dog." } \\
\text { - "Lack of programs here at the end of the } \\
\text { day." } \\
\text { - "More hobby-esque or teachable classes. } \\
\text { Something they can do at home too." } \\
\text { - "Yeah, I would love to share my artwork. } \\
\text { But where?"” }\end{array}$ \\
\hline Task and Environmental Modifications & $\begin{array}{l}\text { - "We should have more tables. It's crowded } \\
\text { and people have no room for their trays." } \\
\text { - "I don't know when class starts." } \\
\text { - "This is dangerous. My head keeps hitting } \\
\text { the back of the machine. I probably won't use } \\
\text { this again." } \\
\text { - "I'm scared of falling backwards." } \\
\text { - "We need more translators. There's a lot of } \\
\text { Spanish speaking seniors." } \\
\text { - "I don't understand sometimes, so I don't do } \\
\text { it." } \\
\text {-"We need better lights and bigger tables. } \\
\text { These lights are too dark, and I can't see the }\end{array}$ \\
\hline
\end{tabular}




\begin{tabular}{|c|c|}
\hline & $\begin{array}{l}\text { puzzles. Also, tell them to bring back the } \\
\text { bigger table." } \\
\text { - "I adapted my own stick. I have a hard time } \\
\text { stabilizing this arm, so this has helped. I don't } \\
\text { know if everyone knows about this." } \\
\text {-"Hurts my back too much when I stand too } \\
\text { long. But I need to stand to see the puzzles." }\end{array}$ \\
\hline Staff training & $\begin{array}{l}\text { - "Some program to help these seniors." } \\
\text { - "We aren't trained in handling seniors with } \\
\text { mental problems." } \\
\text { - "There are a lot of seniors here that needs } \\
\text { help. Staff should be trained to help them." } \\
\text {-"Train volunteers to help. She can't see and } \\
\text { needs help eating." } \\
\text { - "We should have some training materials, } \\
\text { like flyers or something easy and quick." } \\
\text { - "We do a good job with what we know, but } \\
\text { it would be nice if we were better trained." } \\
\text { - "Maybe something that can help us help } \\
\text { them more." } \\
\text {-"There needs to be someone at lunch to help } \\
\text { her. We can't help her all the time." }\end{array}$ \\
\hline More Announcements & $\begin{array}{l}\text { - "I didn't know about it." } \\
\text { - "When did they say that." } \\
\text { - "They need to let us know what's } \\
\text { happening." } \\
\text { - "I didn't know. They should tell us." } \\
\text { - "Where did they put that?" } \\
\text { - "What they don't do already here is } \\
\text { advertising. They have a lot of lovely things } \\
\text { here. But there is no publicity. A lot of } \\
\text { seniors don't know about this place. There's } \\
\text { nothing in the paper that tells us about this } \\
\text { place." } \\
\text {-"[The class] didn't take off. Some of the } \\
\text { blame was on...the marketing of it." }\end{array}$ \\
\hline
\end{tabular}

\section{Discussion}

To enhance social participation in senior centers, it is important to develop strategies to adjust to the varied and changing needs of the older population. The results of this project provide promising ideas on how to evolve the San Marcos Senior Activity Center into a more 
fostering social environment for their seniors. One strategy that showed potential in promoting social participation was getting regular input from seniors on ways to improve their social experiences (See Appendix F for sample assessment). At the end of the project, many seniors expressed increased satisfaction in their experiences at the center as they were given more opportunities to voice their opinions. By providing seniors the opportunity to play a larger and active role at the center, they created their own autonomy and thereby creating their own social role and identity within the facility. This was an important aspect of social participation, as it provided older people a sense of community or feel of belonging, which can translate to higher quality of life (Buffet et al., 2013).

Secondly, this needs assessment illustrates the prospect of using music as an intervention to promote social connectedness. Music provided a social context for a variety of forms of interaction at the center. It allowed seniors to sing and dance together, as well as sparked new conversations between existing and new friends. There is a growing body of evidence that demonstrate significant social and emotional benefits of musical engagement in seniors. It was seen that older people who were more engaged in musical activities experienced more pleasure, and felt more cared for, than those who participated in other leisure activities (Creech, 2019). Additionally, music-related activities offered seniors the feeling of social inclusion, the motivation to join group activities, and establish new friendship bonds (Dominguez-Chavez et al., 2019). Therefore, it is noteworthy for senior centers to design more music-related activities, such as a having a group discussion on the impact of music, recruiting a senior band at the center, collaborating with seniors to create a playlist of their favorite songs, or designing a class on how to use music technology to access music (O'Rourke et al., 2018; Creech, 2019). 
Lastly, this project showed that occupational therapy has the potential to play a significant role in supporting social participation and leisure engagement among communitydwelling older adults. Given their knowledge on health conditions and contextual factors, occupational therapists may be a good addition to the senior center staff as consultants, as they can analyze activities and the environment and modify them to be more supportive and safer for seniors. This ability to adapt to increase engagement is especially important in keeping older adults socially active in the community to prevent further decline in social interaction. There are also implications for research, as there is a need for more knowledge on current community occupational therapy practices and factors that influence social participation interventions (Turcotte et al., 2018).

\section{Limitations}

There were some unforeseen limitations to this project. While interviewing older adults and staff, interview questions had to be reworded multiple times, due to confusion in diction and language barriers. Questions were asked in different ways and specific words left out, which could have changed the meaning of a question. Due to these changes, there may be inconsistencies to the interview responses. Additionally, seniors had a difficult time thinking of new activities that they would like to see at the center. Thus, for future projects, it would be more helpful to provide a list of activities (See Appendix G for a sample list) to assist seniors in answering this question or create a frequent group activity that allows the planning and exploration of different activities at the center. Another limitation was the senior center's requirements for planning events. For instance, event planning usually takes about three months in advance to prepare for due to funding. Thus, because of the short duration of this project, it 
was not possible to implement any new social event or see any big changes, thereby no postinterviews were conducted.

\section{Future Studies}

For future studies, it is recommended that the focus should be on creating an ongoing training program for staff member and volunteers that addresses the impact of aging, cognitive and physical impairments on social and leisure participation and how to adapt activities to promote engagement in seniors. Studies have shown that insufficient training and lack of knowledge about accommodation options were common barriers to participation, thus it is essential for senior center staff to be trained to promote occupational engagement (Padkapayeva et. al, 2017). Since many seniors at this senior center had mild dementia, it would be beneficial for staff to also be trained in identifying potential triggers and behavioral and emotional symptoms, as well as learning different environmental strategies to redirect seniors for safe participation (Alzheimer's Association, 2009). Additionally, it is recommended that future studies implement the proposed recommendations from this project and measure the impact of the enhanced social programming on quality of life for seniors at the San Marcos Senior Activity Center.

\section{Conclusion}

With the rise of an aging population, it is important to identify effective practices that fosters social participation in community-dwelling older adults. The older adult population of today is significantly different than the older adult populations of yesterday and of tomorrow (Lawler, 2011). Thus, it is essential for senior centers to evolve to meet the future needs of the new generation of older adults in order to provide the support they need to remain socially active within their community. The purpose of this project was to evaluate current social programming 
and identify the social needs of the seniors at the San Marcos Senior Activity Center. A decline in number of participants was not a reflection of negative attitudes toward senior services, but was mainly due to lack of available classes of interests, lack of awareness of available opportunities, and from transportation barriers. Music-related activities, such as listening to music and watching live performances, were found to have a transformative effect on seniors' social interaction and engagement at the center. Finally, the results of this project support the development of an occupational therapist's role in promoting healthy aging for communitydwelling older adults in senior centers through evaluating seniors' needs and interests and designing programs around those needs, assisting them with exploring new opportunities to remain engaged in the community, and serving as consultants to the senior center for facility environmental modifications to enhance participation. 


\section{References}

Alzheimer's Association. (2009). Dementia care practice recommendations for assisted living residences and nursing homes. Retrieved from https://www.alz.org/national/documents/brochure_DCPRphases1n2.pdf

American Occupational Therapy Association [AOTA]. (2016). Occupational therapy's role in senior centers. Retrieved from https://www.aota.org/About-OccupationalTherapy/Professionals/PA/Facts/senior-centers.aspx

American Occupational Therapy Association [AOTA]. (2014). Occupational therapy practice framework: Domain and process ( $3^{\text {rd }}$ ed.). The American Journal of Occupational Therapy, 68(Suppl.1), S1-S48.

Buffel, T., Donder, L., Phillipson, C., Dury, S., Witte, N., \& Verte, D. (2013). Social participation among older adults living in medium-sized cities in Belgium: The role of neighbourhood perceptions. Health Promotion International, 29(4), 655-668.

Doi:10.1093/heapro/dat009

Clark, F., Jackson, J., Carlson, M., Chou, C.P., Cherry, B.J., Jordan-Marsh, M., Knight, B.G., Mandel, D., Blanchard, J., Granger, D.A., Wilcox, R.R, Lai, M.Y., White, B., Hay, J., Lam, C., Marterella, A., Azen, S.P. (2012) Effectiveness of a lifestyle intervention in promoting the well-being of independently living older people: Results of the well elderly 2 randomised controlled trial. J Epidemiol Community Health, 66(9):782-90. doi:

10.1136/jech.2009.099754.

Creech, A. (2019). Using music technology creatively to enrich later-life: A literature review. Frontiers in Psychology, 10:117. doi: 10.3389/fpsyg.2019.00117 
Creswell, J. W. (2014), Research Design: Qualitative, Quantitative and Mixed Methods Approaches ( $4^{\text {th }}$ ed.), Thousand Oaks, California: Sage Publication Inc.

Dattilo, J., Lorek, A., Mogle, J., Sliwinski, M., Freed, S., Frysinger, M., \& Shuckers, S. (2015). Perceptions of leisure by older adults who attend senior centers. Leisure Sciences, 37, 373-390. Doi: 10.1080/01490400.2015.1016563

Dominguez-Chavez, C.J., Murrock, C.J., Guerrero, P.I., \& Salazar-Gonzalez, B.C. 2019). Music therapy interventions in community-dwelling older adults with mild cognitive impairment: A pilot study. Geriatric Nursing, 1-6. doi: 10.1016/j.gerinurse.2019.06.004

Eigenschenk, B., Thomann, A., McClure, M., Davies, L., Gregory, M., Dettweiler, U., \& Ingles, E. (2019). Benefits of outdoor sports for society. A systematic literature review and reflection on evidence. International Journal of Environmental Research and Public Health, 16, 937-958. doi: 10.3390/ijerph16060937

Ekel, L.C., \& Peek, S.T., \& Luijkx, K.G. (2017). Diversity in older adults' use of the internet: identifying subgroups through latent class analysis. Journal of Medical Internet Research, 19(5), 1-11. doi: 10.2196/jmir.6853

Ellis, Bronwyn (2018). Music learning for fun and wellbeing at any age! Austrian Journal of Adult Learning, 58(1). Retrieved from http://0b30fejfu.mp01.y.http.go.galegroup.com.prxusa.lirn.net/ps/i.do?p=AONE\&u=lirn55718\&id=GALE $\mid$ A541787081\&v=2.1\&it=r\&sid=e bsco

Eronen, J., von Bonsdorff, M., Rantakokko, M., \& Rantanen, T. (2014). Environmental facilitators for outdoor walking and development of walking difficulty in community 
dwelling older adults. European Journal of Ageing, 11 (1), 67-75. doi:10.1007/s10433013-0283-7

Figueiro, M. (2001). Lighting the way: A key to independence. AARP Andrus Foundation. Retrieved from https://www.lrc.rpi.edu/programs/lightHealth/AARP/pdf/AARPbook2.pdf

Fox, K., Morrow-Howell, N., Herbers, S., Battista, P., \& Baum, C. (2017). Activity disengagement: Understanding challenges and opportunities for reengagement. Occupational Therapy International, 1-7, doi: 10.1155/2017/1983414

Gill, P., Stewart, k., Treasure, E., \& Chadwick, B. (2008). Methods of data collection in qualitative research: Interviews and focus groups. British Dental Journal, 204, 291-295. doi: $10.1038 /$ bdj.2008.192

Herald, D. (2019, April 16). How music enrichment can change the lives of seniors. Gale OneFile: News. Retrieved from http://0b30fe31y.mp01.y.http.go.galegroup.com.prxusa.lirn.net/ps/i.do?p=STND\&u=lirn55718\&id=GALE $\mid$ A582673348\&v=2.1\&it=r\&sid=e bsco

Hostetler, A.J. (2011). Senior centers in the era of the "Third age:" Country clubs, community centers, or something else? Journal of Aging Studies, 25(2), 166-176. doi: 10.1016/j.jaging.2010.08.021

Hurley, M., Dudziec, M., Kennedy, B., Anderson, L, Jackson, I., Koskela, S., Gallagher, W., \& Jones, F. (2014). Increasing the health, activity and participation levels of people attending day centres. International Journal of Therapy and Rehabilitation, 21(7), 310317. doi: 10.12968/ijtr.2014.21.7.310 
ICAA Forum. (2015). Strategies for bringing wellness to people with cognitive decline. International Council on Active Aging. Retrieved from https://www.icaa.cc/conferenceandevents/forums/reports/2015stretegiesforbringingwellnesstopeoplewithcognitivedecline.pdf

Jefferson, B.J. (1999). Factors affecting participation in senior center programs. UNLV Theses, Dissertations, Professional Papers, and Capstones, 310. Retrieved from https://digitalscholarship.unlv.edu/cgi/viewcontent.cgi?article=1204\&context=thesesdisse rtations

Kitada, L.R (2016). Cooking with roots: How older adults strengthen connection with younger generations through recipe sharing. Scripss Senior Thesis. 766. Retrieved from https://pdfs.semanticscholar.org/1e95/a947e58f79c725e23b1c601dd458d1e482cf.pdf

Lawler, K. (2011). Transforming senior centers into $21^{\text {st }}$ century wellness centers. AARP Louisiana Project. Retrieved from https://www.artsmidwest.org/sites/default/files/MeaningfulExperiencesAgingAudiencesHandout2.pdf

Leitner, M.J \& Leitner, S.F. (2012). Leisure in later life (4 ${ }^{\text {th }}$ ed.). Urbana, IL: Sagamore Publishing. Retrieved from https://sagamorepub.com/sites/default/files/201807/6757li.pdf

Lorek, A., Dattilo, J., Mogle, J., Freed, S., Frysinger, M., \& Chen, S. (2017). Staying connected: Recommendations by older adults concerning community leisure service delivery. Journal of Park and Recreation Administration, 35(3), 94-112. doi: 10.18666/JPRA2017-V35-I3-7682 
Marshfield community and senior center needs assessment survey. (2012). Retrieved from http://ci.marshfield.wi.us/LibraryProject/Survey_Results.pdf

Morita, K. \& Kobayashi, M. (2013). Interactive programs with preschool children bring smiles and conversation to older adults: time-sampling study. BioMedical Central, 13, 111. doi: $10.1186 / 1471-2318-13-111$

Novek, S., Meneck, V., Tran, T., \& Bell, S. (2013). Social participation and its benefits. Centre on Aging. Retrieved from https://www.gov.mb.ca/seniors/publications/docs/senior_centre_report.pdf

Nyman, A., \& Isaksson, G. (2015). Togetherness in another way: Internet as a tool for togetherness in everyday occupations among older adults. Scandinavian Journal of Occupational Therapy, 22, 387-393. doi: 10.3109/11038128.2015.1020867

O`Rourke, H.M., Collins, L., \& Sidani, S. (2018). Interventions to address social connectedness and loneliness for older adults: A scoping review. BMC Geriatrics, 18, 214. doi: 10.1186/s12877-018-0897-X

Padkapayeva, K., Posen, A., Yazdani, A., Buettgen, A., Mahood, Q., \& Tompa, E. (2017). Workplace accommodations for persons with physical disabilities: evidence synthesis of the peer-reviewed literature. Disability and Rehabilitation, 39:21, 2134-2147. doi: $10.1080 / 09638288.2016 .1224276$

Papageorgiou, N., Marrquis, R., Dare, J., \& Batten, R. (2016). Occupational therapy and occupational participation in community dwelling older adults: A review of the evidence. Physical and Occupational Therapy in Geriatrics, 34(1), 21-42. doi:

$10.3109 / 027703181.2015 .1109014$ 
Portney, L. \& Watkins, M. (2015). Foundations of Clinical Research (3 $3^{\text {rd }}$ ed.). Philadelphia: F.A. Davis Company.

San Diego County. (2015). Intergenerational programs directory. Retrieved from https://www.sandiegocounty.gov/hhsa/programs/ais/documents/IGDirectory.pdf

Schell, B.A, Gillen, G., \& Scaffa, M.E. (2014). Willard and Spackman's Occupational Therapy. Philadelphia: Lippincott Williams \& Wilkins.

Seaman, J. (n.d.). Accommodations for cognitive and academic deficits. Retrieved from https://adayinourshoes.com/wp-content/uploads/Accommodations-for-Cognitive-andAcademic-Deficits.pdf

Smallfield, S. \& Molitor, W.L. (2018). Occupational therapy interventions supporting social participation and leisure engagement for community dwelling older adults: A systematic review. American Journal of Occupational Therapy, 72, 7204190020p1-7204190020p8. doi:10.5014/ajot.2018.030627

Targeted News Service. Seniors get big benefits form outdoor activities. (2017, June 30). Retrieved from http://0b30fe9zw.mp01.y.http.go.galegroup.com.prxusa.lirn.net/ps/i.do?p=STND\&u=lirn55718\&id=GALE|A497456410\&v=2.1\&it=r\&sid=e bsco

Turcotte, P., Carrier, A., Roy, V., \& Levasseur, M. (2018). Occupational therapists' contribution to fostering older adults' social participation: A scoping review. British Journal of Occupational Therapy. 81(8), 427-449. doi: 10.1177/0308022617752067

Vivoda, J.M \& McGuire, M.M. (2017). Participant satisfaction and the impact of senior center services in Lucas County, Ohio. Scrips Gerontology Center. Retrieved from https://sc.lib.miamioh.edu/bitstream/handle/2374.MIA/6181/Participant\%20Satisfaction 
$\% 20$ and $\% 20$ the $\% 20$ Impact $\% 20$ of $\% 20$ Senior $\% 20$ Center $\% 20$ Services $\% 20$ in $\% 20$ Lucas $\% 2$ 0County\%20Ohio.pdf

Yang, C. \& Conroy, D. (2019). Feasibility of an outdoor mindful walking program for reducing negative affect in older adults. Journal of Aging and Physical Activity, 2019, 27, 18-27. doi: 10.1123/japa.2017-0390 
APPENDIX A

Verbal Consent Script for Interview 
Hello, my name is Diana. Thank you for agreeing to talk to me today. I am interested in understanding your experience at the senior center. I will be asking you some questions which you are free to answer in any way you wish. If a question is unclear to you, please feel free to ask me to explain it. I would like to record the interview, so I don't miss anything that you say, but will not include your name on any documents or in the recording. Your answers will be kept confidential. Is it okay if I record our discussion? 
APPENDIX B

Proposed Interview Questions 


\section{$\underline{\text { Initial Interview Questions }}$}

Questions for attendees:

- Are there things that make participating in activities hard? (age related conditions, environment, cost, transportation issues, scheduling)

- What is your favorite activity at the center?

O What do you like most about this activity?

o What would you change about the activity to make it better?

- What other classes or activities would you like to see offered at the center?

- Do you feel that there are opportunities to be a part of planning activities at the center?

\section{Questions for staff members:}

- What aspects of the senior center do you like the best?

- What are some challenges at the center? (such as funding, policies, scheduling)

- What are the strengths of the senior center?

- What programs or changes would you like to see be offered at the center?

\section{Potential Post Interview Questions}

\section{Questions for attendees:}

- Did you enjoy being a part of planning the activities at the center?

- Are there any further suggestions that you would like to make?

- What barriers are you currently experiencing?

- Were there any changes in your social relations at the center?

\section{Questions for staff members:}

- Are you still facing the same barriers after the changes?

- Are there any further suggestions that you would like to make?

- Did you notice any differences in social interactions among staff and attendees? What about between attendees?

*Adapted from two studies (Novek et al., 2013; Hurley et al., 2014) 
APPENDIX C

Observation Guideline 


\begin{tabular}{|c|c|c|c|}
\hline Are seniors involved in: & Yes & No & If yes, how? \\
\hline \multicolumn{4}{|l|}{ Program planning } \\
\hline \multicolumn{4}{|l|}{ Providing Services } \\
\hline \multicolumn{4}{|l|}{ Evaluating programs } \\
\hline Programs: & \multicolumn{3}{|c|}{ Notes: } \\
\hline \multicolumn{4}{|l|}{ Most popular classes } \\
\hline \multicolumn{4}{|l|}{ Schedule of classes offered } \\
\hline \multicolumn{4}{|l|}{$\begin{array}{l}\text { Demographic of attendees } \\
\text { (gender, \# of attendees in that } \\
\text { class, roles) }\end{array}$} \\
\hline \multicolumn{4}{|l|}{$\begin{array}{l}\text { Barriers on participation } \\
\text { (environmental: physical } \\
\text { space, structural barriers) }\end{array}$} \\
\hline Social Behaviors: & $\begin{array}{r}\text { How are } \\
\text { other (bo } \\
\text { How }\end{array}$ & $\begin{array}{l}\text { ting with each } \\
\text { cooperation) } \\
\text { attendees } \\
\text { ng? }\end{array}$ & $\begin{array}{l}\text { Any barriers? (language, } \\
\text { different interests, conflict) }\end{array}$ \\
\hline \multicolumn{4}{|l|}{ Staff-user interaction } \\
\hline User-user interaction & & & \\
\hline
\end{tabular}

*Adapted from a study (Novek et al., 2013) 
APPENDIX D

Potential Lunch Activities 


\section{Lunch activity - "Around the World"}

Goal: To increase social interaction by having seniors share stories about where they are from, where they want to travel or have traveled to

Frequency and duration: Twice a week for 4 weeks (this can be changed )

Materials Needed: large world map, flag pins (2 different colors), pen

- This activity can be led by anyone (staff member or volunteers)

\section{Outline:}

- Week 1 - Introduction

○ Introduce world map and explain that it will be posted on the lunch wall for a month

- Encourage seniors to come up and pin the countries that they have traveled to (red pins) or where they are from/countries of origin (yellow pins) with their names on it

- Announce to seniors that they should prepare and think about their traveling stories to share for next week

- Activity leader, staff, and volunteers should also prepare

- Have seniors make and decorate paper flags, to be put up in the common areas as decoration

- Week 2 - Share traveling stories

o Have seniors share their stories within their table for first 5-10 minutes

- Have leader or other volunteers walk around each table to encourage/start conversation

- After 10 minutes, activity leader will go to each table to ask for one person to stand up and share their stories in front of the lunch room (or from their lunch table if they prefer)

- If no one at the table wants to participate, have the leader, staff, or volunteer share

- Potential questions to ask:

- Where have you traveled to?

- What was the most interesting food or favorite food that you ate there?

- Would you go back?

- If you could live somewhere else in the world for a year, where would you go?

○ Ask seniors to bring something that they would like to share (a souvenir, a cultural artifact, etc.) for next week

- Leader, staff, volunteers should also bring something

- Week 3 - Continue sharing traveling stories \& share personal item

- Have seniors continue sharing their stories

- Have seniors share their personal item

- Questions to ask them about their item:

- What item did you bring to share today? 
- Why is it important to you?

- Where did you get it?

\section{Potential adaptations to promote participation:}

- World map placement should be at a safe height level for fall prevention

- If many seniors cannot pin the countries on the wall, lay the map on a table for easier pinning or marking

- Use colored dot stickers instead of pins if seniors have decreased strength and cannot push the pins into the wall

- Supply thick markers for easier handling (or build up handles with foam cylinders if needed)

- If seniors are not able to walk around to each table to show their item, encourage another senior to assist 


\section{Lunch Activity - "Music Exploration"}

Goal: To discuss the impact of a song on daily routines and to explore different types of music

Materials Needed: Laptop, phone, or any technology that has access to music

\section{Group discussion Outline:}

- Idea \#1: Ask seniors to name their favorite songs and explain why they like it

○ Potential questions to ask:

- What do you like about it?

- When and where were you when you first heard this song?

- Ask them to sing a chorus or any parts of the song OR play a snippet of the song for everyone to hear

- Ask them to bring in a $\mathrm{CD}$, vinyl, poster, or any relevant item to share

- Why is this meaningful to you?

- Idea \#2: Ask seniors on how they weave music into a typical day.

- Ask seniors to explain their daily routine and what songs they like to listen to during that activity

○ For instance, when they:

- Cook

- Exercise

- Clean the house

- Relax

- Eat

- Driving

- Play a snippet of the songs

- Potential questions to ask:

- What do you like about this song?

- How do you feel when you hear this song?

- Why do you prefer this type of music for this activity?

- Provide pen and paper for seniors to write down these songs

- Staff should also provide a handout with these song suggestions

- Idea \#3: Provide a class on how to use technology (computer and phones) to access music, such as Spotify or YouTube

○ During class, staff should provide handouts of simple directions on how to access music

- Option: Add visual screenshots for each step to make directions easier to follow (example given below)

- STEP 1:

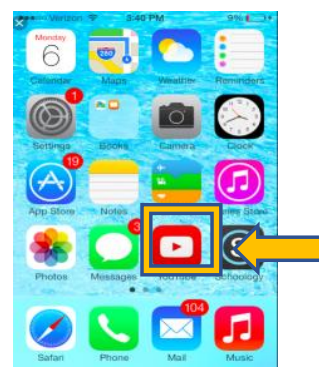

\section{Click on} YouTube

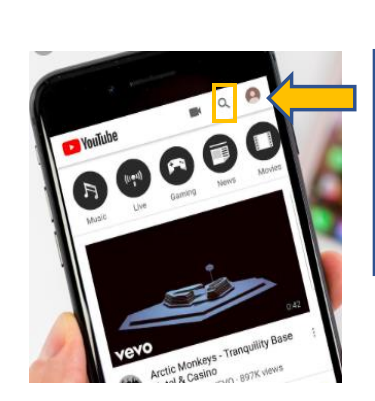

STEP 2:

Click on
Magnifying Glass
and enter artist
and/or song name




\section{Social Event - "Do It Yourself Ice Cream"}

Goal: For seniors to share their favorite ice cream flavors and to work together to make their own ice cream

Duration: 10-15 minutes to make ice cream

Materials Needed: Half \& half, Sugar, rock salt, ice and vanilla, large gallon Ziploc bag, sandwich size Ziploc bag

Optional: Toppings

\section{Outline:}

- WEEK 1: Ask seniors on what their favorite ice cream is and have a short discussion

○ Potential questions:

- Why is this your favorite ice cream?

- Where can you buy this?

- What toppings do you like?

- What ingredients do you need to make it?

- Have you ever made your own ice cream?

- Have seniors agree on TWO ice cream flavors to make

- Encourage seniors to use the computer lab to find and print the recipes for next week (This can be a potential technology class: "How to look for recipes")

- Train staff/volunteers so that they can assist seniors in making ice cream

- WEEK 2: Make Ice Cream

- Staff should print same extra recipe handouts for those that did not print them out

- Lay out all ingredients on table in order from left to right

- Have seniors decide among themselves on their roles for this activity (ex: one person can read the directions, one person can pour the flour into the bag, etc.)

- Provide towel/cloth to wrap the large Ziploc bag for easier handling

- Have seniors take turns rocking the bags back and forth until ice cream texture is created

○ Serve into bowls and enjoy!

\section{Potential adaptations to promote participation:}

- Provide number signs (ex: STEP 1, STEP 2, STEP 3, etc.) next to each ingredient to assist seniors in following directions

- Have seniors rock the bags back and forth on the table to simplify task 
Yield: 4 servings

\section{Do It Yourself Ice Cream Recipe}

\section{Ingredients:}

Ice Cream base:

2 cups whole milk

$1 / 2$ cup granulated sugar

1 tablespoon vanilla extract

10 cups ice
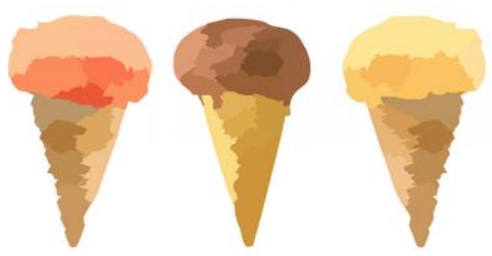

8 tablespoons rock salt

\section{$\underline{\text { Directions }}$}

YouTube Link: https://www.youtube.com/watch?v=N4ztYjFxwmI

1. Combine milk, sugar, and vanilla extract in a sandwich size Ziploc bag and seal tightly.

2. Put a scoop of ice, tablespoons ice cream rock salt, and the sandwich bag (from step 1) into the large Ziploc bag. Seal tightly.

3. Wrap the large Ziploc bag with a cloth for easier handling

4. Rock the bag back and forth on the table until contents thicken into ice cream, about 1015 minutes.

5. Remove the smaller Ziploc bag with the ice cream from the outer bag and serve into small bowls! Enjoy! 


\section{Lunch Activity - "Food Exploration"}

Goals: To create new social connections through culinary traditions

\section{Outline:}

- Idea \#1 - Intergenerational Recipe Sharing

- Ask seniors to name their favorite home-cooked meals, desserts, or snacks

○ Questions to ask:

- Why is that your favorite?

- What does it remind you of?

- Do you have a special family recipe? If so, can you share it with the group? (Encourage them to go to the computer lab to type and print their recipe to share with others)

- Do you eat this on special occasions or on an everyday-basis?

- Where can you buy these ingredients?

- Are there any local restaurants that you can find these meals?

$\circ$ If the recipe is simple and does not require baking or cooking, have a cooking social!

- Staff can provide ingredients or have seniors bring in their own ingredients (if they have it)

- Here are some examples of no-bake desserts: https://tasty.co/topic/no-bake-desserts

- Or seniors can decorate their own desserts, such as a cookie or cupcake

- Have seniors bring in or pick their favorite toppings

○ Have seniors record themselves at home on how to make this recipe or show a video clip found online

- Provide pen and paper so that seniors can write down the recipe

- $\quad$ Idea \# 2 - Food preferences

○ Discussion: What are their food preferences?

- Taste (sweet, sour, bitter, salty, and umami (savory))

- Smell

- Texture

- Ask seniors to bring in their favorite snacks or candy (enough to share with their table) and discuss why they like it

o Questions to ask:

- When do you like to eat this? Is there a particular time of the day or event that you like to eat it on?

- Idea \#3 - Technology class on how to find new recipes or local restaurants online

○ Have seniors search for the closest grocery outlets that has the ingredients to their recipe and compare the costs

- Look for grocery or restaurant coupons online

- Explore new local restaurants

\section{Potential adaptations/accommodations to promote participation:}

- For multi-step recipes, provide a handout of simple directions with visual screenshots to help seniors follow directions 
- Enhancing visual contrast

- Place light objects against darker backgrounds, or vice versa to create contrast and make it "stand out"

- Example: white dinner plate against a dark blue placemat

- Provide additional time for individuals who may need them

- Build up handles of eating utensils for easier grasping 


\section{Social Event - Diversity Month}

Goal: A month long event to celebrate and learn about 4 different cultures of our seniors!

Frequency \& Duration: Once a week for five weeks starting in April

\section{Outline:}

- Staff responsibilities:

- Find at least 2 seniors to lead each week's discussion

An example of how each week may look like:

- Week 1 - Introduction to Culture

$\circ$ What is culture?

- The system of shared beliefs, values, customs, behaviors, and artifacts of a group of people

○ How do we see culture?

- Art

- Foods (how we eat food, where, when, with whom)

- Traditions, rituals/ceremonies (birthdays, coming of age, holidays)

- Religion (rituals, holidays)

- Music/dance

- Dress (men vs. women, work vs. at home, during holidays)

- Values/behavior

- Cultural identity - What culture are you a part of?

- Provide examples: sports fan, Trekkie (Star Trek fans), foodie (likes to look for new food experiences as a hobby), dog lovers

- Have seniors with similar cultural identities group up together to discuss

- Have seniors pick at least 4 cultures or sub-cultures to celebrate for the next couple weeks and at least 2 seniors to lead each week

- Do the "That's Me" activity and have seniors share examples of how they fit into that generation

- Potential ideas for Week 2 - Week 5

- Have the lead seniors introduce the culture they are a part of

- What is it?

- Why is this culture meaningful to them

- Have the lead seniors share their favorite cultural memories

- Have lead seniors decorate the common areas with pictures of that culture (examples include country flag, popular foods, attire, celebrities/famous people, etc.)

- Have seniors research and provide fun facts about that culture

- Staff should also research additional facts and look for potential activities that relate to that culture 
- Ask seniors to bring in small objects of cultural significance (for example: pictures, dress attire, snacks, recipes, movies, posters, tickets, etc.) to share or demonstrate

- Questions to ask about their object

- Why is this meaningful?

- What does it tell about you? Your culture?

- Have seniors bring in a popular cultural dish or have the lunch caterer make one

- Have seniors bring in examples of music from their own culture or heritage, or hire local cultural musical groups to provide live music

- Have lead seniors sing their favorite cultural song first and then encourage other seniors to sing along (must provide lyrics)

- Have lead seniors act or role-play their favorite scene from a movie or game

$\circ$ Provide resources on diversity-related activities and events in the local community

○ Have seniors dress up in cultural attire (if they have it)

- Have lead seniors perform a cultural dance (if they know it)

- Show a multicultural film

- Have lead seniors provide suggestions on their favorite local restaurants

- Have seniors design a fun picture booth that represents their culture 


\section{Thar's mol}

The following descriptions are traits of different generations. We will read the descriptions out loud and if you feel that it fits you, raise your hand and say "That's me".

Generation 1:

This group experienced inflation and unemployment stress. They do not trust institutions for long-term security. They can be discouraged about society, but they are clever and resourceful. They are comfortable with change and clear about the meaning of balance in their lives. They work to live, not live to work. Core values are diversity, thinking globally, fun, informality, and self-reliance.

\section{Generation 2:}

This group values privacy and sharing inner thoughts may be challenging. Members believe in hard work and "paying their dues" before their achievement is recognized. Their word is their bond and they value honesty. Communication is formal. This group is not wasteful and values saving and making do. They are hard-working, economically aware and generally trustful of the government. They are optimistic and willing to sacrifice. Patience is a virtue. Their slogan is "I will cope". Their core values are dedication, hard work, and duty before pleasure.

\section{Generation 3:}

This group grew up in a time of economic prosperity and against a background of rebellion. They value peer competition and strive for challenge and change. This group will fight for a cause they believe in. They work well in teams and do not like having rules for the sake of rules. Health and personal growth are important. They respect letters but they get overwhelmed with mail so they probably prefer email. They like phones and answering machines. Their slogan is "The ME generation".

\section{Generation 4:}

This group has a firm desire to know the reason behind what is happening and what they do. Members are rarely impressed by new technology. They are optimistic about the future and realistic about the present. They have a good work ethic. They like to know why they are doing something and do not take blind orders. They like to see how they made a difference in others' lives or in their own personal life. Having patience is really a problem because they want to see immediate results and action. This group likes all senses to be stimulated with colors, movement, and music.

\section{Answers:}

Generation 1 = Generation X (born 1965-1980)

Generation 2 = Silent Generation (born 1922-1945)

Generation 3 = Baby Boomers (born 1946-1964)

Generation $4=$ Generation Y (1981 to 1996)

*Taken from Clark et al., 2012 


\section{Social Event - Hobby Fair}

Goal: To introduce seniors to new potential leisure activities

\section{Outline:}

- Organize an event in the parking lot or common areas (such as cafeteria or hallways) for participants to bring in representations, tools, or examples of their hobbies, such as fishing memorabilia, photos, ice skates, quilts, artwork, plants, etc.

○ Participants may include staff members, volunteers, current seniors at the center, or anyone in the general community including family and friends

- Provide a table for each participant to showcase their hobbies or work

- Encourage participants to share with other seniors:

○ How long they have practiced

- Where they usually practice at

- Who or how they were introduced to this hobby

$\circ$ If this activity requires more than two people

- If it does require 2 people, what are their roles

- The materials needed to start hobby

$\circ$ And give a demonstration

- Allow seniors to try each hobby out if possible

- For example: if a senior is interested in fishing, encourage them to hold the fishing hook and mimic the action of reeling to experience first-hand if they enjoy it

- Ask senior attendees or volunteers to walk around center and spread awareness about event

- Hand out certificates or a ribbon to all of the participants to recognize their hard work! 


\section{Needs Assessment Survey}

Goal: To evaluate existing programs, learn participant's interests and preferences, and identify what will enhance senior engagement in order to plan appropriate programs

Frequency: Bi-annually

\section{Outline:}

- Announce during classes and lunchtime about the goal of the survey

- Encourage seniors to fill out the short survey (provided below) about their experiences in exchange for a free lunch ticket or one free class

- If a senior is unable to fill it out due to health limitations, a staff member/volunteer can assist with filling it out 


\section{San Marcos Senior Activity Center Survey}

Are you involved in any activities offered here?

$\square$ Yes

If "No" why not? (Check all that apply.)

$\square$ Don't know what services/activities are offered
$\square$ Not interested in current services/activities
$\square$ Too busy
$\square$ Lack of Transportation
$\square$ Don't know anyone there
$\square$ Other:

What activities do you currently participate in?

$\begin{array}{ll}\square & \text { Card Games } \\ \square & \text { Bingo } \\ \square & \text { Puzzles } \\ \square & \text { Shoot Pool } \\ \square & \text { Arts \& Craft } \\ \square & \text { Computer Use/Training } \\ \square & \text { Fitness Classes } \\ \square & \text { Dancing Classes }\end{array}$

\begin{tabular}{l}
$\square$ Free health screenings \\
$\square$ Tax Preparation \\
\hline$\square$ Lunch \\
\hline$\square$ Social Events during lunch \\
\hline$\square$ Educational Programs \\
$\square$ Intergenerational Activities \\
$\square$ Other:
\end{tabular}

How can we improve this activity?

$\square$ Provide adapted equipment (examples: built up handles, magnifying glass, etc.)

Such as:

$\square$ Slow down the pace of the activity

$\square$ Change environment (examples: smaller or bigger rooms, bigger tables, more or less lighting, adjustable tables)

Such as:

$\square$ Change the date or time it is offered

Change to:

$\square$ Provide more announcements on this activity

$\square$ Increase staff support

$\square$ Provide handouts during class

$\square$ Other:

What other classes or social event would you like to see at the senior center?

*adapted by http://ci.marshfield.wi.us/LibraryProject/Survey_Results.pdf 


\section{$\underline{\text { Survey Music Preferences }}$}

Goal: To create a personalized music playlist during lunchtime to enhance their social experiences

Materials Needed: A printout (provided below)

\section{Outline:}

- During lunchtime, have a staff member/volunteer walk around to each table and ask seniors on their music preferences

- Start conversation about their favorite songs and bring other seniors into the conversation by asking questions like:

○ "Do you also know this song?"

○ "Do you know any other songs from this artist?"

- If seniors cannot think of any songs at the moment, ask them to prepare a list of their favorite songs at home and bring it back to the center

- Explain to seniors that there will also be a list at the front desk where they can write down their music suggestions

- $\quad$ Add songs onto Spotify Playlist "San Marcos Senior Center Playlist - created by Diana Dinh"

○ https://open.spotify.com/playlist/71ZjzGyihwNMflF4O1BmUb

- Any person can add songs onto this playlist, as long as they have a Spotify account (This can be a potential technology class: "How to use technology to access music")

- This playlist can be played via browser using the link above, or through a phone app 
Music Suggestions

Please write down any songs or types of music that you would like to hear during lunch time

1.

2.

3.

4.

5.

6.

7.

8.

9.

10.

11.

12.

13.

14.

15.

16.

17.

18.

19.

20.

21. 
APPENDIX E

Additional Examples of Adaptations and Accommodations 


\section{Examples of Adaptations and Accommodations}

\section{Physical}

- Provide chair cushions for ideal positioning so seniors can participate in activities

- $\quad$ Build up handles with a foam rubber cylinder for easier grasping of pens or eating utensils

- Provide maulstick to stabilize tremoring hands in painting classes

- Provide cushion (or any other thick and soft material) for activities that require using the wrist

\section{Cognitive}

- Slow pace of an activity

- Repeat directions

- Provide visual aids to supplement oral directions for an activity

○ Handouts

○ Checklist

- Limit the amount of information given during each class

\section{Visual}

- Increase bright lighting and contrast for better visibility

- Simplify walls

- Provide hand-held magnifiers

- Print flyers in big font to increase ability to read print

\section{Environmental}

- Tables

$\circ$ Change the position of tables to avoid reflection/glares

- Add additional tables in the lunch room

- Provide wheelchair-accessible or adjustable tables

- Floors

○ Provide rubber mats in outdoor gym for safety 
APPENDIX F

Visual Aid Sample 


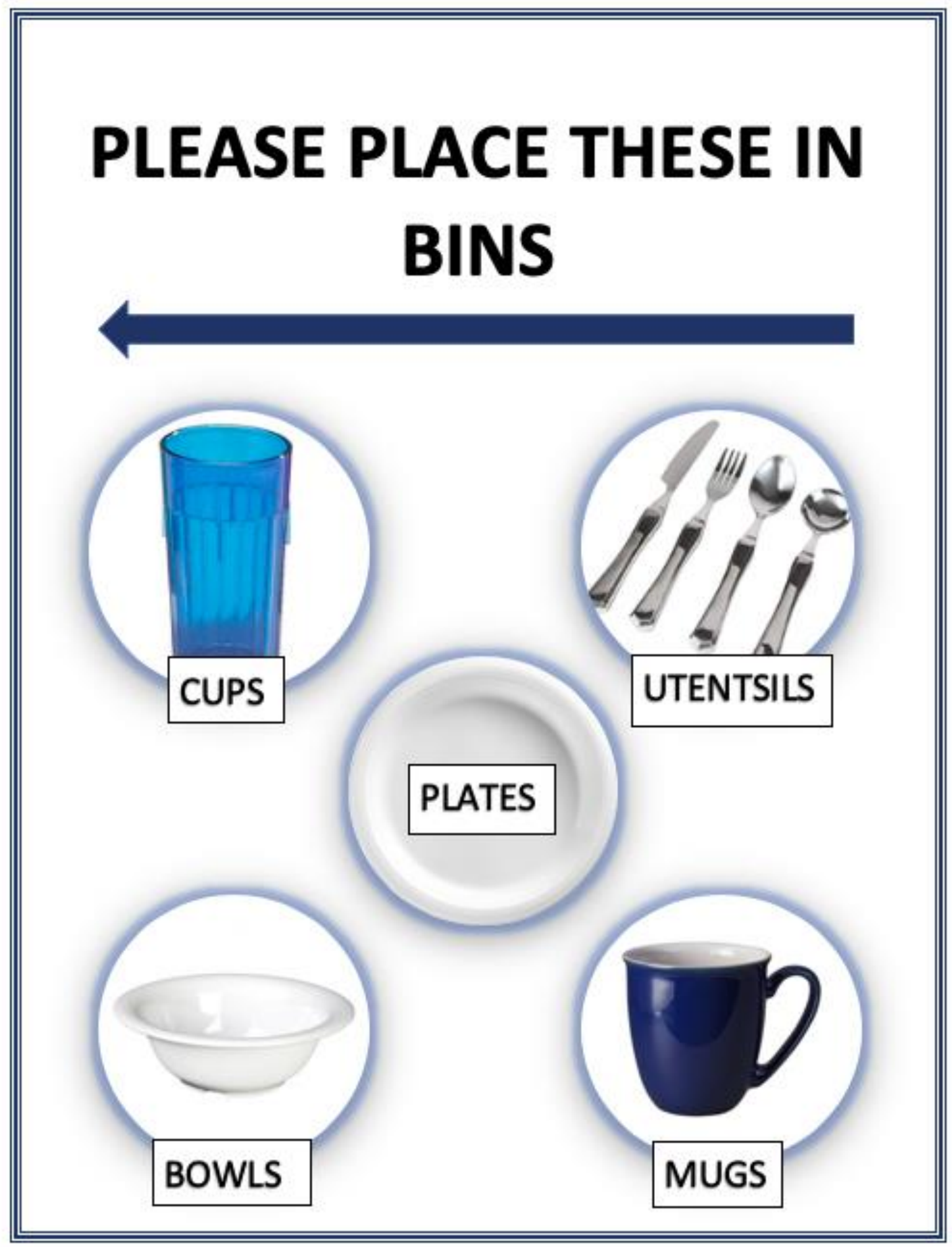


APPENDIX G

Activity List Sample 
What activities would you possibly participate in at the senior center in the FUTURE? (Please circle)

- Book club

- Group exercise classes

- Play card games

○ Cribbage

○ Bridge

- Educational Classes

○ Fall Prevention

- Safe Driving

- Adaptive equipment

- Aging in place: home modifications

- Fitness classes

- Board games

○ Chess

- Checkers

○ Monopoly

- Others - Please list

- $\quad$ Arts \& $\overline{\text { Craft classes }}$

- Scrapbook

- Bulletin Board

- Decorating lunch room

o Painting

- Shoot Pool

- Bingo
- Dancing classes

○ Ballroom

- Square

o Line

o Hula

- Outdoor activities

○ Walking Path

- One day travel opportunities

- Gardening

- More social events

- Singing karaoke

- Learning a musical instrument

○ Guitar

○ Ukulele

- Piano

- Drums

- Watching movies

- Technology Classes

- Computer

- Smartphones

- Digital Camera

- Intergenerational Activities

- Jigsaw puzzles

- Wii

- Other 